\title{
Nitrosonium Ions as Constituents of Dinitrosyl Iron Complexes with Glutathione Responsible for their S-Nitrosating Activity
}

\author{
Anatoly F. Vanin* \\ N.N. Semenov Institute of Chemical Physics, Russian \\ Academy of Sciences, Moscow; Institute for Regenerative \\ Medicine, I.M. Sechenov First Moscow State Medical \\ University, Moscow, Russia \\ *Corresponding author: Anatoly F. Vanin, N.N. \\ Semenov Institute of Chemical Physics, Russian Academy \\ of Sciences, Moscow; Institute for Regenerative Medicine, \\ I.M. Sechenov First Moscow State Medical University, \\ Moscow, Russia
}

Received: October 03, 2018; Accepted: November 05, 2018; Published: November 12, 2018

\begin{abstract}
It has been established that the S-nitrosating activity of biologically active binuclear dinitrosyl iron complexes with glutathione (B-DNIC-GSH, formula $\left.\left[\left(\mathrm{GS}^{-}\right)_{2} \mathrm{Fe}_{2}(\mathrm{NO})_{4}\right]\right)$ is determined by the presence in these complexes of nitrosonium ions $\left(\mathrm{NO}^{+}\right)$. The release of the latter from B-DNIC-GSH during their decomposition in acid media is accompanied by the formation of S-nitrosoglutathione (GS-NO) both in the presence and in the absence of oxygen, whereas at neutral $\mathrm{pH}$ nitrosonium ions released from B-DNIC are converted into nitrite anions by hydrolysis. It has been shown that the concentrations of nitrite anions and GS-NO correlate exactly with the concentration of $\mathrm{Fe}(\mathrm{NO})_{2}$ fragments of $\mathrm{B}-\mathrm{DNIC}$, being equivalent to the concentration of $50 \%$ of nitrosyl ligands in B-DNIC. The rest $50 \%$ of nitrosyl ligands are released from B-DNIC in the form of neutral molecules of NO. The data obtained are interpreted in terms of the $d^{7}$ electronic configuration of iron in B-DNIC in the framework of our hypothetical mechanism of $\mathrm{Fe}(\mathrm{NO})_{2}$ formation in B-DNIC during interaction of bivalent iron with neutral molecules of $\mathrm{NO}$ and thiols.
\end{abstract}

Keywords: Dinitrosyl iron complexes; S-nitrosothiols; Nitrosonium ion; Nitric oxide

\section{Abbreviations}

B- or M-DNIC: Binuclear or Mononuclear Dinitrosyl Iron Complexes; EPR: Electron Paramagnetic Resonance; GS-NO: S-nitrosoglutathione; RS-NO: S-nitrosothiols.

\section{Introduction}

It has been established that the mononuclear and binuclear forms of dinitrosyl iron complexes with thiol-containing (RS-) ligands (M- and B-DNIC with chemical formulas $\left[(\mathrm{RS})_{2} \mathrm{Fe}(\mathrm{NO})_{2}\right]$ and $\left[\left(\mathrm{RS}^{-}\right)_{2} \mathrm{Fe}_{2}(\mathrm{NO})_{4}\right]$, respectively) manifest a broad range of biological activities, which resemble those of nitric monoxide (NO), one of the most universal endogenous regulators of metabolic processes in living organisms. These complexes exert strong vasodilator and, correspondingly, hypotensive effects on animals and man [1-4]. They suppress platelet aggregation and thrombosis [5,6], accelerate healing of skin woulds $[7,8]$, stimulate penile erectile activity in animals [9], trigger the synthesis of heat-shock proteins [10], possess potent antioxidant activity [11-13], modulate the functional activity of certain genes [14,15], key proteins and enzymes [16-19], initiate S-nitrosation of thiols [20-23], inhibit propagation of Coxsackie-3 virus $\left(2^{\text {Apro }}\right)$ in animal hearts [24], suppress the growth of endometrial tumours in animals with experimental endometriosis [25], etc. And, last but not least, they inhibit the growth of cultured tumour cells $[26,27]$ and cease malignant growth in animals $[27,28]$. All these findings leave hope that DNIC with thiol-containing ligands holds considerable promise as a basis in the design of medicinal drugs possessing a broad range of therapeutic activities. Several novel
DNIC-based drugs are successfully used in the clinical practice for relieving hypertension crises and accelerating healing of skin wound $[8,29]$.

There is evidence that biological activity of DNIC with thiolcontaining ligands is related to their ability to play the role of donors of $\mathrm{NO}$ and nitrosonium ions $\left(\mathrm{NO}^{+}\right)$in animal and human organisms. The NO-donating capacity of these DNIC can be illustrated by the fact that inhibition of the heme-containing protein guanylate cyclase, one of the main targets of NO, fully eliminates their vasodilatory effect [30]. As far as the ability of DNIC with thiol-containing ligands to generate nitrosonium ions possessing S-nitrosating activity is concerned, it was established for both isolated thiol-containing proteins and their intracellular counterparts [21-23]. This process was significantly attenuated in the presence of iron chelators inhibiting DNIC synthesis both in the presence and in the absence of oxygen [22,23]. The latter circumstance fully refutes the hypothesis according to which S-nitrosation of proteins induced by DNIC is a result of oxidation of $\mathrm{NO}$ released from DNIC to $\mathrm{NO}_{2}$ and subsequent formation of nitrogen trioxide responsible for S-nitrosation of thiols [31].

The ability of DNIC with thiol-containing ligands to donate NO and $\mathrm{NO}^{+}$is determined by their electronic structure characterized by the $\mathrm{d}^{7}$ electronic configuration of iron (in the Enemark-Feltham classification it is described by the formula $\left.\left[\mathrm{Fe}(\mathrm{NO})_{2}\right]^{7}[32]\right)$. The hypothetical mechanism of M-DNIC formation in a reaction between $\mathrm{Fe}^{2+}$, thiols and gaseous NO is shown in Scheme 1: 


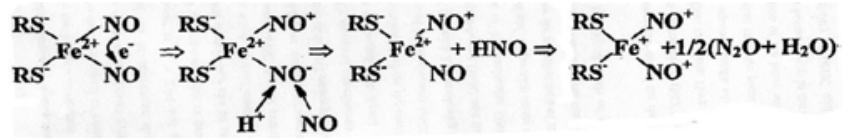

Scheme 1: The hypothetical mechanism of formation of the paramagnetic (EPR-active) mononuclear form of DNIC with thiol-containing (RS) ligands by a reaction of gaseous $\mathrm{NO}$ with the $\mathrm{Fe}^{2+}$-thiol mixture [33-35].

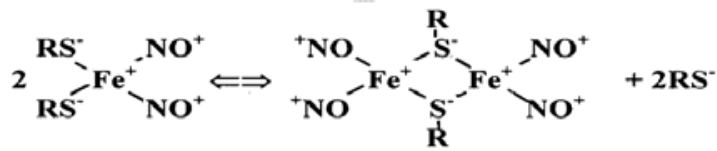

Scheme 2: The interconversion of $\mathrm{M}$ - and B-DNIC with thiol-containing ligands [42].

The overall reaction of M-DNIC formation can thus be presented as follows (Reaction 1):

$2 \mathrm{RS}^{-}+\mathrm{Fe}^{2+}+3 \mathrm{NO}+\mathrm{H}^{+} \Rightarrow\left[\left(\mathrm{RS}^{-}\right)_{2} \mathrm{Fe}^{+}\left(\mathrm{NO}^{+}\right)_{2}\right]+1 / 2\left(\mathrm{~N}_{2} \mathrm{O}+\mathrm{H}_{2} \mathrm{O}\right)$ (Reaction 1).

As can be seen, this reaction involves three $\mathrm{NO}$ molecules, in addition to two thiol molecules and $\mathrm{Fe}^{2+}$ ions. This hypothesis was supported by experimental data [36]; the hypothetical formation of nitrous oxide by this reaction was demonstrated in [37].

In the framework of this mechanism, two molecules of $\mathrm{NO}$ as free-radical species enter the disproportionation reaction (mutual oxidation-reduction), which is terminated by their conversion into nitrosonium and nitroxyl $\left(\mathrm{NO}^{-}\right)$ions. The latter leave the the coordination sphere of iron in the form of a nitroxyl molecule to be further converted into nitrous oxide. The ligand site adjacent to the iron atom is immediately occupied by the other NO molecule; in the presence of thiols, this reaction is terminated by the formation of paramagnetic mononuclear dinitrosyl iron complexes (M-DNIC) with thiol-containing ligands characterized by the formula [(RS )$\left._{2} \mathrm{Fe}^{+}\left(\mathrm{NO}^{+}\right)_{2}\right]$ and the EPR signal at $\mathrm{g}_{\text {aver. }}=2.03$ (the so-called 2.03 signal) $\left(g_{\perp}=2.04, g_{\|}=2.014\right)$ recorded for the first time in living organisms as early as the 1960's [38-40].

Factually, this formula reflects solely the distribution of the spin density and is fully consistent with the results of the EPR analysis of M-DNIC according to which unpaired electronic density in M-DNIC is predominantly localized on the iron atom with the $\mathrm{d}^{7}\left(\mathrm{Fe}^{+}\right)$electronic configuration, while the spin density on nitrosyl and thiol-containing ligands is negligibly small. As regards the distribution of total electron density in M-DNIC, the transfer of the lone electron pair from thiol sulfur atoms possessing high $\pi$-donor activity to nitrosyl ligands diminishes their positive charge and prevents their hydrolysis due to binding of nitrosyl ligands to negatively charged hydroxyl ions, which makes M-DNIC more stable in aqueous media [41].

As regards B-DNIC, these complexes are generated according to Scheme 2 as a result of lowering of thiol concentration in the solution or, more specifically, the concentration of thiols that are ionized at the thiol group and possess the ability to bind to DNIC carrying a positively charged iron ion.

There is evidence that in these complexes, too, the distribution of spin density is very similar to that in M-DNIC.

\section{$\left[\left(\mathrm{RS}_{2} \mathrm{Fe}^{+}\left(\mathrm{NO}^{+}\right)_{2}\right] \Rightarrow \mathrm{Fe}^{2+}+\mathrm{NO}+\left(\mathrm{RS}^{-\mathrm{NO}^{+}}\right)+\mathrm{RS}\right.$}

Scheme 3: The hypothetical chemical equilibrium between M-DNIC with thiolcontaining ligands and their constituent components with the $\mathrm{d}^{7}$ electronic configuration of the iron atom for DNIC with thiol-containing ligands $[41,42]$.

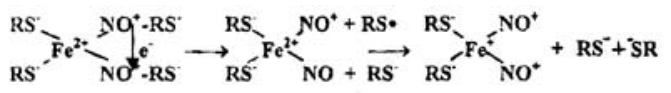

Scheme 4: The hypothetical mechanism of synthesis of M-DNIC with thiol-containing ligands by a reaction between $\mathrm{Fe}^{2+}$ ions, thiols (RS) and S-nitrosothiols (RS- $\mathrm{NO}^{+}$) [33,44].

\section{$\left.\mathrm{Fe}^{+}\left(\mathrm{NO}^{+}\right)_{2}\right] \Rightarrow \mathrm{Fe}^{2+}+\mathrm{NO}+\mathrm{NO}^{+}$}

Scheme 5: The hypothetical decomposition of the iron-dinitrosyl fragment of $\mathrm{B}-\mathrm{DNIC}$ in the absence of thiols and the generation of the nitrite anion.

After establishing of the chemical equilibrium between M-DNIC and its constituent components, thiol-containing ligands leave the coordination sphere of iron as a result of which the dinitrosyl fragment of the latter regains the formula $\mathrm{Fe}^{+}\left(\mathrm{NO}^{+}\right)_{2}$ and the chemical equilibrium (Scheme 3) is reestablished:

According to Scheme 3, one nitrosyl ligand converts into a NO molecule as a result of the electron transfer from $\mathrm{Fe}^{+}$, while the other ligand (the nitrosonium ion) binds to thiol to form S-nitrosothiol (see Scheme 2) of the formula $\left(\mathrm{RS}^{-} \mathrm{NO}^{+}\right)$. After decomposition of M-DNIC, half of nitrosyl ligands are released in the form of neutral molecules, while the other half leaves the complex in the form of nitrosonium ions, which enter into a reaction to begin with thiols because of their high affinity for nitrosonium ions and thereupon with hydroxyl ions, if thiols are in deficit. This interaction gives RSNO or nitrite anions.

As regards B-DNIC, it is reasonable to suggest that the chemical equilibrium between B-DNIC and their constituent components established after the conversion of B-DNIC into M-DNIC (Scheme 2) is similar to that for M-DNIC, i.e., B-DNIC also possess an ability to effectively donate both $\mathrm{NO}$ and $\mathrm{NO}^{+}$.

The conversion of M-DNIC with the thiol-containing ligand cysteine into S-nitrosocysteine (Cys-NO) was established in our laboratory as long ago as 1990's in experiments where heating of solutions of M-DNIC with cysteine to $60-70^{\circ} \mathrm{C}$ in the air followed by their sharp acidification resulted in decomposition of M-DNIC and fast (within several minutes) appearance of S-nitrosocysteine molecules; their concentration correlated with the concentration of $50 \%$ of nitrosyl ligands present in original M-DNIC [20]. Our more recent studies demonstrated that anaerobic and aerobic heating of $0.3 \mathrm{mM}$ solutions of B-DNIC with glutathione (B-DNIC-GSH) acidified to $\mathrm{pH} 1.0$ upon heating to $80^{\circ} \mathrm{C}$ results in their decomposition as could be judged from the predominant accumulation of gaseous NO (during 6h) or soluble GS-NO (during 40-50 min) in degassed or non-degassed hermetically closed chambers of the Thunberg apparatus, respectively [43]. We hypothesized that in the former case (in the absence of oxygen) both nitrosyl ligands in iron-dinitrosyl fragments of B-DNIC were reduced to $\mathrm{NO}$ by $\mathrm{Fe}^{2+}$ ions, while in the latter case (in the presence of oxygen) $\mathrm{Fe}^{2+}$ ions were rapidly oxidized to $\mathrm{Fe}^{3+}$ by atmospheric oxygen and thus lost their ability to reduce 


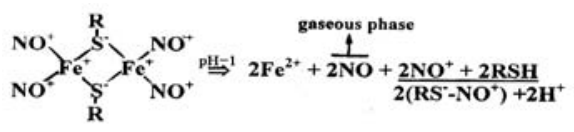

Scheme 6: The irreversible decomposition of B-DNIC with glutathione used as a RS- ligand in an aqueous solution $(\mathrm{pH} 1.0)$ and subsequent accumulation of GS-NO (RS-NO+). The NO molecules released from B-DNIC pass into the gaseous phase.

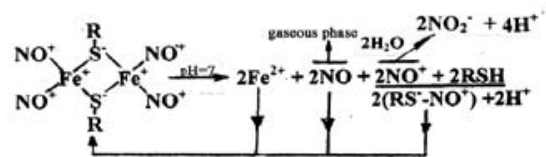

Scheme 7: The chemical processes underlying accumulation of nitrite anions in B-DNIC and partial regeneration of the latter from their constituent components $\left(\mathrm{Fe}^{2+}, \mathrm{NO}, \mathrm{NO}^{+}\right.$and thiols (glutathione)) at neutra ("physiological") $\mathrm{pH}$.

nitrosonium ions to NO. As a result, both nitrosyl ligands were released from B-DNIC in the form of nitrosonium ions; their binding to glutathione gave GS-NO.

In the aforecited studies, we did not examine the possibility of release of a half of nitrosyl ligands in the form of neutral molecules of $\mathrm{NO}$ and the other half in the form of nitrosonium ions from decomposing M- or B-DNIC (Scheme 3) in the presence and in the absence of oxygen. In order to destroy the uncertainty about the validity of this hypothesis, in this study I examined the possibility of GS-NO and nitrite formation as well as the NO release from B-DNICGSH as a result of heating of their solutions to $40-80{ }^{\circ} \mathrm{C}$ at acidic or neutral values of $\mathrm{pH}$ or under effect of h-chloromercurybenzoate (PCMB), a selective reagent for thiol groups.

\section{Materials and Methods}

\section{Materials}

Ferrosulfate (Fluka, Buchs, Switzerland), reduced glutathione and sodium nitrite (Sigma, St. Louis, USA) were used. Gaseous NO was obtained in a reaction of ferrosulfate with sodium nitrite in $0.1 \mathrm{M} \mathrm{HCl}$ with subsequent purification of the final product by low-temperature sublimation in an evacuated glass system [42].

\section{Synthesis of B-DNIC with glutathione}

Our protocol of DNIC synthesis was based on the ability of S-nitrosothiols (RS-NO) (in our case, of GS-NO) to generate DNIC with thiol-containing ligands (RS) in a reaction of RS-NO with bivalent iron and thiols (in our case, glutathione) (Scheme 4):

According to this Scheme, single-electron oxidation-reduction of two RS-NO molecules in the course of their binding to $\mathrm{Fe}^{2+}$ was accompanied by their decomposition and, as a consequence, formation of M-DNIC and their further conversion into B-DNIC as a result of M-DNIC dimerization.

In our study, DNIC synthesis was performed using the following protocol [45]. Glutathione ( $40 \mathrm{mM})$, ferrosulfate $(20 \mathrm{mM})$ and sodium nitrite $(20 \mathrm{mM})$ were added consecutively to $10 \mathrm{ml}$ of $15 \mathrm{mM}$ HEPES buffer. Glutathione caused acidification of test solutions as could be evidenced from the sharp decrease of $\mathrm{pH}$ to 3.0-3.5; further addition of $\mathrm{FeSO}_{4}$ and the resulting decrease of $\mathrm{pH}$ led to complete dissolution

\section{$\left[\left(\mathrm{RS}_{2} \mathrm{Fe}^{-1}\left(\mathrm{NO}^{+}\right)_{2}\right] \Rightarrow \mathrm{Fe}^{2+}+\mathrm{NO}+\mathrm{NO}^{-}+2 \mathrm{RS}\right.$}

Scheme 8: The chemical equilibrium between M-DNIC with thiol-containing ligands and their constituent components having the $\mathrm{d}^{9}$ electronic configuration of the iron atom in DNIC with thiol-containing ligands suggested in [50-53].

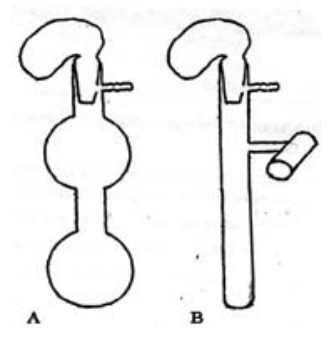

Figure 1: The Thunberg apparatus used in this study.

of ferrosulfate without any formation of water-insoluble $\mathrm{Fe}^{2+}$ hydroxide complexes. Moreover, the acidification was concomitant with conversion of nitrite into GS-NO as could be evidenced from the increase of the main characteristic absorption band of GS-NO at $334 \mathrm{~nm}$ and the appearance of an additional weak band at $546 \mathrm{~nm}$ ( $\varepsilon=0.94 \mathrm{M}^{-1} \mathrm{~cm}^{-1}$ and $0.017 \mathrm{M}^{-1} \mathrm{~cm}^{-1}$, respectively). Judging from the intensity of these absorption bands, after $1-1.5 \mathrm{~h}$ the solution contained $20 \mathrm{mM}$ GS-NO suggesting that the whole amount of nitrite was converted into GS-NO as a result of its interaction with glutathione. The subsequent sharp increase in $\mathrm{pH}$ to neutral values was accompanied by the formation of M-DNIC-GSH and their further conversion into B-DNIC-GSH (Scheme 2). Optical measurements performed after passage of test solutions through filter paper and removal of residual hydroxide iron complexes $(10 \mathrm{mM})$ non-incorporated into B-DNIC demonstrated that after preliminary overnight storage of test samples the reaction was complete within several hours and was terminated by accumulation of B-DNIC-GSH $(\sim 10 \mathrm{mM})$.

It may be inferred from these data (Scheme 4) that the formation of one iron-dinitrosyl fragment requires two molecules of GS-NO, which are decomposed in the course of M-DNIC synthesis resulting in a release of one molecule of GSH and one thyil radical, i.e., the synthesis of one iron-dinitrosyl fragment of B-DNIC requires three molecules of free (i.e., non-incorporated into B-DNIC) GSH and one molecule of GSH bound to B-DNIC as a bridging ligand.

\section{Heating of B-DNIC solutions under aerobic and anaerobic conditions}

In this series of our experiments, we investigated B-DNICGSH solutions at acidic (1-2) or neutral (7.0-7.4) values of $\mathrm{pH}$. The solutions were loaded into a Thunberg apparatus made of heatresistant glass (Figure 1A), which allowed experimentation both in the presence and in the absence of oxygen. Our experiments were carried out in a non-degassed and degassed Thunberg apparatus placed onto a water bath and heated to $40-80{ }^{\circ} \mathrm{C}$.

The experimental protocol included the use of a modified version of the Thunberg apparatus supplied with a hermetically closed cylinder-shaped quartz cuvette soldered up to the apparatus and placed along the light beam of the spectrophorometer in such a way that its axis was perpendicular to the axis of the cylinder-shaped part 


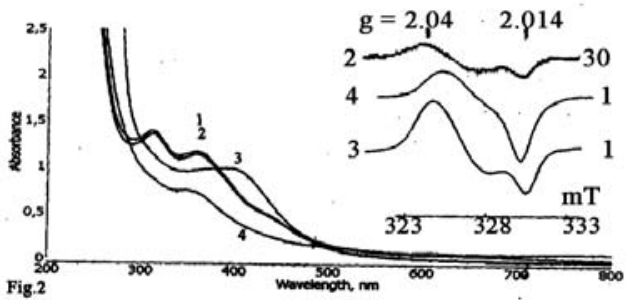

Figure 2: Left panel: The preservation of the absorption spectrum of B-DNIC-GSH $(0.3 \mathrm{mM})$ after the increase in $\mathrm{pH}$ from 7.3 to 10.0 (Spectra 1 and 2, respectively) and the conversion of B-DNIC-GSH into M-DNIC-GSH (Spectrum 3) or DNIC with hydroxyl ions (Spectrum 4) after addition of excess GSH to B-DNIC-GSH solutions (10:1)and the increase in the $\mathrm{pH}$ of B-DNIC$\mathrm{GSH}$ to 10.0 or after a mere increase in $\mathrm{pH}$ to $12.0-13.0$, respectively. Right panel (inset): The EPR spectra (2-4) of B-DNIC-GSH solutions characterized by the adsorption spectra 2-4 (left panel), respectively. All EPR spectra were recorded at $77 \mathrm{~K}$. The amplification of the radiospectrometer (in rel. units) is indicated in the right part of the Figure.

of the apparatus (Figure 1B). This design enabled easy measurements of optical absorption spectra of $\mathrm{NO}$ in the gaseous phase.

Quantitative measurements of NO included a comparison of the amplitudes of four equidistant, equally intensive absorption bands of NO in the gaseous phase at $220-190 \mathrm{~nm}[43,46]$ described in to the amplitudes of identical bands in the reference absorption spectra at predetermined pressure of gaseous NO followed by calculations of NO concentration $(\mathrm{m} / \mu)$ based on the use of the MendeleevClapeyron equation for ideal gases:

\section{$\mathrm{m} / \mu=\mathrm{PV} / \mathrm{RT}$}

where $P, V, m, R, T$ and $\mu$ are the pressure, volume $(100 \mathrm{~mL})$, mass, gas constant, temperature (293K) and molecular mass of NO, respectively.

\section{EPR and optical measurements of B-DNIC solutions}

EPR spectra of B-DNIC solutions were measured at $77 \mathrm{~K}$ in a quartz Dewar vessel filled with liquid nitrogen using a modified RadioPan EPR spectrometer (Poland) (microwave power, $5 \mathrm{~mW}$; modulation amplitude, $0.2 \mathrm{mT}$ ). The concentration of paramagnetic M-DNIC-GSH generated from B-DNIC-GSH was determined by double integration of EPR signals. A solution of M-DNIC-GSH of known concentration ( $\mathrm{pH}$ 11.0) was used as a reference sample.

Optical measurements of B- and M-DNIC-GSH were performed on a UV-2501PC spectrophotometer (Shimadzu Europa GmbH, Germany) in a flat quartz cuvette with an optical path of $10 \mathrm{~mm}$ or in a quartz cylinder-shaped cuvette with an optical path of $40 \mathrm{~mm}$ soldered up to the Thunberg apparatus (Figure 1B). All measurements were performed at ambient temperature. The possibility to use an additional cylinder-shaped cuvette made is possible to measure optical absorption spectra in both the gaseous phase and in solutions loaded into a degassed Thunberg apparatus in the absence of air.

\section{Results}

\section{Description of B-DNIC-GSH preparations}

The ratio between free (non-incorporated into DNIC) GSH molecules and iron atoms in B-DNIC-GSH (3:1) was far too low to initiate the conversion of B-DNIC into M-DNIC according to Scheme
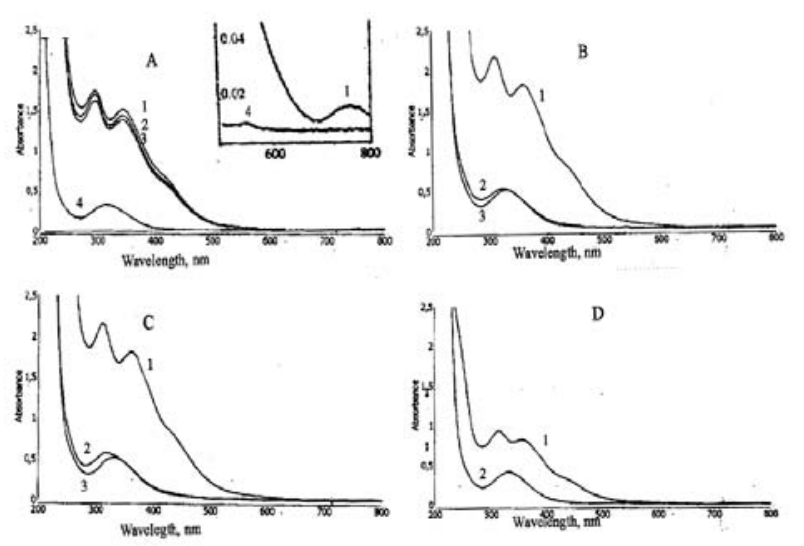

Figure 3: The conversion of B-DNIC-GSH into GS-NO during decomposition of B-DNIC-GSH induced by heating of their acidified solutions (data from absorption spectral measurements).

Panel A: 2 and 30 min after acidification of the original $0.4 \mathrm{mM}$ solution of B-DNIC-GSH (pH 7.4) (Spectrum 1) to $\mathrm{pH} 1.0$ (Spectra 2 and 3, respectively) and a subsequent 30 -s increase in temperature from ambient to $80^{\circ} \mathrm{C}$ (Spectrum 4). The inset shows the weak absorption bands of GS-NO and B-DNIC at 543 and $768 \mathrm{~nm}$ (Curves 4 and 1). Panels B and C: after acidification of the $0.5 \mathrm{mM}$ solution of B-DNIC-GSH to $\mathrm{pH} 1.0$ (Spectrum 1) and subsequent 30 -s incubation at $80^{\circ} \mathrm{C}$ (Panel B) or 25-min incubation at $40^{\circ} \mathrm{C}$ (Panel $\mathrm{C}$ ) in the presence and in the absence of air (Spectra 2 and 3 , respectively). Panel $\mathrm{D}$ : The absorption spectrum of a $9 \mathrm{mM}$ solution of B-DNIC-GSH acidified to $\mathrm{pH} 1.0$ after its 40 -fold dilution with distilled water (Spectrum 1) or subsequent incubation in the air $\left(15 \mathrm{~min}, 80^{\circ} \mathrm{C}\right.$ ) and 20 -fold dilution with distilled water (Spectrum 2).

2 as could be evidenced from the lack of any significant contribution of absorption bands of M-DNIC at 390nm to the overall optical absorption spectrum of B-DNIC, which displayed the presence of intense absorption bands of B-DNIC-GSH at 310 and $360 \mathrm{~nm}$; their extinction coefficients $(\varepsilon)$ calculated per one iron atom in B-DNIC were equal to 4600 and $3700 \mathrm{M}^{-1} \mathrm{~cm}^{-1}$, respectively (Figure 2, left panel, Curve 1) [42]. This absorption spectrum did not change after the increase in $\mathrm{pH}$ to 10.0 which provided complete ionization of the thiol group of glutathione (Figure 2, left panel, Curve 2). However, in this case ionization was accompanied by the appearance of a weak EPR signal (the 2.03 signal) mentioned above (Figure 2, right panel (inset), Spectrum 2). As can be seen, the complexes responsible for this signal, viz., M-DNIC-GSH, were able to incorporate no more than $1 \%$ of iron originally present in B-DNIC.

The increase in $\mathrm{pH}$ to $12.0-13.0$ caused drastic changes in the absorption spectra of B-DNIC, which manifested themselves in disappearance of absorption bands at 310 and $360 \mathrm{~nm}$ and appearance of a weak band at $380 \mathrm{~nm}$ (Figure 2, left panel, Curve 4). Other changes included disappearance of the 2.03 signal and appearance of an EPR signal characteristic of M-DNIC with hydroxyl ligands described in [47] (Figure 2, right panel (inset), Spectrum 4). The intensity of this signal corresponded to incorporation of the whole amount of iron originally present in B-DNIC-GSH into appropriate M-DNIC.

The conversion of B-DNIC-GSH into M- and B-DNIC with hydroxyl ligands was fully reversible: after the decrease of $\mathrm{pH}$ from 12-13 to neutral values as a result of which the absorption spectrum of the solution again resembled that of B-DNIC-GSH.

Effective conversion of B-DNIC-GSH into M-DNIC occurred 


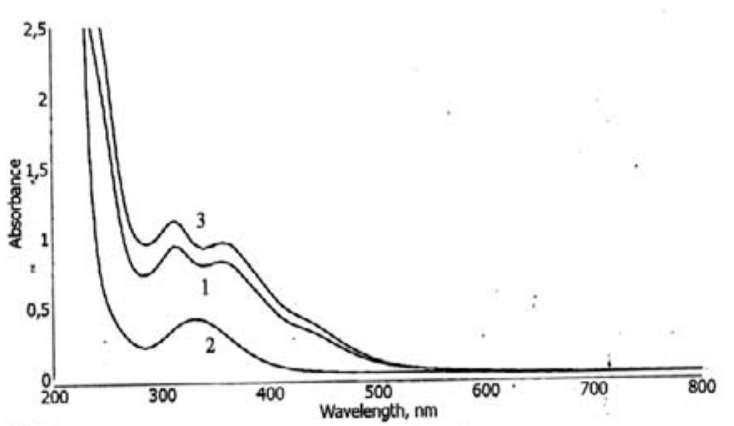

Figure 4: The conversion of B-DNIC-GSH (Spectrum 1) into GS-NO (Spectrum 2) and, reversely, into B-DNIC-GSH (Spectrum 3).

after the increase in the concentration ratio of free glutathione to iron in B-DNIC-GSH to 10 with a concomitant increase in $\mathrm{pH}$ to 10.0. Under these conditions, the whole amount of B-DNIC iron was converted into M-DNIC as could be evidenced from the intensity of its 2.03 signal (Figure 2, right panel, Specrum 3). This phenomenon correlated with a virtually complete disappearance of characteristic absorption bands of B-DNIC at 310 and $360 \mathrm{~nm}$ and the appearance of an absorption band at 390nm characteristic of M-DNIC-GSH (Figure 2, left panel, Spectrum 3).

In the absence of the $\mathrm{pH}$ increase responsible for ionization of thiol groups of glutathione, M-DNIC-GSH were formed in neglibly small amounts, as could be judged from very low intensity of their characteristic 2.03 signal and the predominance in their absorption spectra of characteristic absorption bands of B-DNIC-GSH at 310 and $360 \mathrm{~nm}$.

These data suggest that the DNIC-GSH preparations used in this study were characterized by the 3:1 ratio of free glutathione and DNIC iron, i.e., were predominantly represented by the binuclear form.

\section{Formation of GS-NO during decomposition of B-DNIC-} GSH induced by heating of their acidified solutions

As it was stated earlier in the Introduction chapter, the idea to perform heating of acidified solutions of B-DNIC-GSH was prompted by the results of our earlier experiments where aqueous solutions of M-DNIC with cysteine were heated to $60-70{ }^{\circ} \mathrm{C}$ under aerobic conditions with a subsequent decrease of $\mathrm{pH}$ to 1.0 [20]. This procedure was accompanied by disappearance of the 2.03 signal characteristic of the $\mathrm{M}$ - and appearance of a characteristic absorption band of S-nitrosocysteine at $334 \mathrm{~nm}$.

Similar results were obtained in my experiments on $0.4 \mathrm{mM}$ solutions of B-DNIC-GSH acidified to $\mathrm{pH} 1.0$ and heated subsequently to $80^{\circ} \mathrm{C}$ in the air in a non-degassed Thunberg apparatus. These studies established a very fast (30s) and complete disappearance of the absorption spectrum of B-DNIC-GSH and an appearance of a band at $334 \mathrm{~nm}$ and a weak band at $543 \mathrm{~nm}$ characteristic of GS-NO instead of two absorption bands at 310 and $360 \mathrm{~nm}$ characteristic of B-DNIC (Figure 3, Panel A). The intensity of the bands at $334 \mathrm{~nm}$ and $543 \mathrm{~nm}$ corresponded to the GS-NO concentration of $0.4 \mathrm{mM}$ (as calculated from the values of the extinction coefficients for the absorption bands at 334 and $543 \mathrm{~nm}$ equal to 0.94 and $0.02 \mathrm{M}^{-1} \mathrm{~cm}^{-1}$ ) suggesting that GS-NO formation was initiated by a release of $50 \%$ of nitrosyl ligands from $\mathrm{Fe}(\mathrm{NO})_{2}$ in the form of $\mathrm{GSH}-$ bound $\mathrm{NO}^{+}$ions. The rest $50 \%$ might be released in the form of neutral molecules of $\mathrm{NO}$, which is in perfect agreement with the experimental data (Figure 3).

A natural question arises: could the formation of GS-NO really be induced by oxidation of NO molecules released from B-DNIC-GSH to nitrogen dioxide by air oxygen and subsequent S-nitrosation of GSH by nitrogen trioxide as was postulated in [31]? My experiments on heating of $0.5 \mathrm{mM}$ acidified solutions of B-DNIC-GSH to $80^{\circ} \mathrm{C}$ in a degassed Thunberg apparatus (i.e., in the absence of oxygen) completely disproved this hypothesis. Under the given experimental conditions, the complexes were rapidly (within the first 30s) decomposed to be further converted into GS-NO $(0.5 \mathrm{mM})$ (Figure 3, Panel B, Spectrum 3)! A very similar phenomenon was observed in my experiments where prior to heating of B-DNIC-GSH solutions oxygen was removed by passing the solutions through a neutral gas (in our case, argone) (data not shown). This phenomenon can be attributed exclusively to the involvement of $\mathrm{NO}^{+}$ions as constituent components of B-DNIC in GS-NO formation (judging from Scheme 3 , their concentration was equivalent to the concentration of $50 \%$ of all nitrosyl ligands present in B-DNIC).

In exactly the same amount corresponding to $50 \%$ of nitrosyl ligands present in B-DNIC GS-NO were found in $0.5 \mathrm{mM}$ acidified solutions of B-DNIC heated to $40^{\circ} \mathrm{C}$ irrespective of the presence or absence of oxygen in the Thunberg apparatus (Figure 3, Panel C, Spectra 2 and 3), or in acidified solutions of B-DNIC heated to $80^{\circ} \mathrm{C}$ in the presence of oxygen when used at higher $(9 \mathrm{mM})$ concentrations (Figure 3, Panel D, Spectrum 2). The difference between these experiments and those described above was in that the formation of GS-NO and the decomposition of B-DNIC took a longer time for their completion. In B-DNIC solutions heated to $40^{\circ} \mathrm{C}$, GS-NO formation was complete within 18-20 min, whereas that established upon heating of $9 \mathrm{mM}$ solutions of B-DNIC to $80^{\circ} \mathrm{C}$ lasted $15 \mathrm{~min}$. At low $(0.2-0.1 \mathrm{mM})$ concentrations of B-DNIC, GS-NO (0.2-0.1 mM) were formed within a course of several seconds (data not shown).

It is important to note that the position of the peak of the shortwave band of GS-NO formed from decomposing B-DNIC was observed at exactly $334 \mathrm{~nm}$, however, only in experiments on heating of B-DNIC solutions under anaerobic conditions (Figure 3, Panels $B$ and C, Spectra 3). Under aerobic conditions, the shortwave peak of this absorption band was shifted by $5-10 \mathrm{~nm}$ (Figure 3, Panels B and $C$, spectra 2), which was especially apparent in the latter case as a result of superposition of the absorption bands of $\mathrm{Fe}^{3+}$ ions with a peak at $302 \mathrm{~nm}$ onto the absorption band of GS-NO. The appearance in B-DNIC solutions of $\mathrm{Fe}^{3+}$ ions was induced by oxidation of $\mathrm{Fe}^{2+}$ ions released from decomposing B-DNIC-GSH by oxygen.

At ambient temperature, the incubation of acidified solutions of B-DNIC-GSH was unaccompanied by their decomposition, at least during the first 30min (Figure 3, Panel A, Spectra 1-3).

The time of decomposition of $0.5 \mathrm{mM}$ solutions of B-DNIC-GSH at $80^{\circ} \mathrm{C}$ increased dramatically with the increase in the concentration of free (non-incorporated into B-DNIC) GSH concomitantly with the increase in the concentration ratio between B-DNIC-GSH-bound iron and free GSH (to 10:1). Under these conditions, B-DNIC fully retained their stability for at least $30 \mathrm{~min}$. 


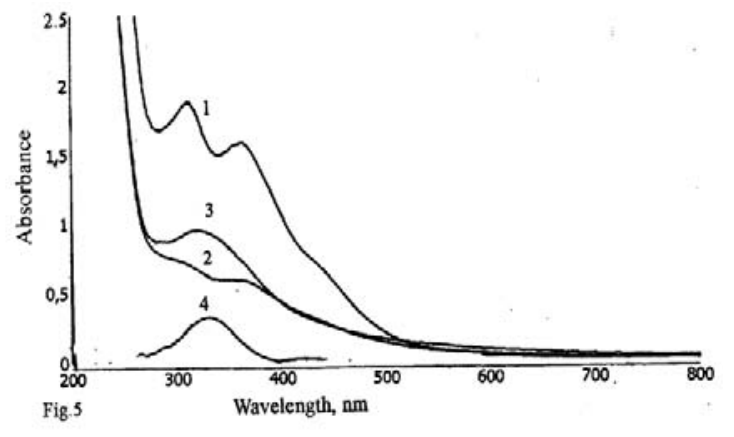

Figure 5: The successive conversion of B-DNIC-GSH into nitrite and GS-NO during heating of $0.5 \mathrm{mM}$ solutions in the air $\left(80^{\circ} \mathrm{C}, 1 \mathrm{~h}\right)$ at $\mathrm{pH} 7.3$ followed by addition of $2 \mathrm{mM}$ GSH.

Spectrum 1: original solutions of B-DNIC-GSH; Spectrum 2: the same after heating; Spectrum 3: after subsequent addition of GSH; Spectrum 4: the absorption band at $334 \mathrm{~nm}$ obtained by subtraction of Spectrum 2 from Spectrum 3 hypothetically related to GS-NO and corresponding to its $0.5 \mathrm{mM}$ concentration.

The results obtained in this study effectively rule out the possibility [31] that S-nitrosation of thiols (in our case, of GSH) induced by decomposition of B-DNIC (in our case, B-DNIC-GSH) are caused by oxidation of $\mathrm{NO}$ released from B-DNIC to $\mathrm{NO}_{2}$ and subsequent S-nitrosation of free thiol (in our case, GSH) by the $\mathrm{NO}-\mathrm{NO}_{2}$ adduct, nitrogen trioxide $\left(\mathrm{N}_{2} \mathrm{O}_{3}\right)$.

The GS-NO formed upon decomposition of B-DNIC could be reconverted into B-DNIC according to Scheme $4[33,44]$ (Figure 4). To achieve this, $15 \mathrm{mM}$ glutathione and $15 \mathrm{mM} \mathrm{FeSO}_{4} \times 7 \mathrm{H}_{2} \mathrm{O}$ were added to a $10 \mathrm{mM}$ solution of GS-NO obtained after decomposition of $10 \mathrm{mM}$ B-DNIC and a subsequent increase in $\mathrm{pH}$ to neutral values. The concentration of B-DNIC formed in these solutions $10 \mathrm{~min}$ thereafter was $5 \mathrm{mM}$, as could be evidenced from the intensity of the absorption band at 360nm (Figure 4, Spectrum 3). These findings altogether suggest that the formation of one $\mathrm{Fe}(\mathrm{NO})_{2}$ fragment in B-DNIC requires two molecules of GS-NO (Scheme 4).

Heating of $9 \mathrm{mM}$ solutions of B-DNIC-GSH acidified to $\mathrm{pH} 1.0$ $\left(80^{\circ} \mathrm{C}, 15 \mathrm{~min}\right)$ was accompanied by the formation of $9 \mathrm{mM}$ GS-NO after which $15 \mathrm{mM}$ GSH and $15 \mathrm{mM}$ ferrosulfate were added to GS$\mathrm{NO}$ with a subsequent increase of $\mathrm{pH}$ to neutral values. The optical spectra of B-DNIC-GSH solutions (Curves 1-3) were recorded at 40-, 20- or 20-fold dilution with distilled water, respectively.

\section{Formation of nitrite during irreversible decomposition of B-DNIC with glutathione induced by heating in the air to $80^{\circ} \mathrm{C}$ at neutral $\mathrm{pH}$}

The decomposition of $0.5 \mathrm{mM}$ B-DNIC-GSH after heating to $80^{\circ} \mathrm{C}$ was also observed at neutral $\mathrm{pH}$ as could be evidenced from the disappearance of the absorption bands at 310 and $360 \mathrm{~nm}$. Under aerobic conditions, this process was complete within $1 \mathrm{~h}$ (Figure 5 , Spectrum 2), while in the absence of oxygen the decomposition of B-DNIC did not take place at all. Subsequent addition of $2 \mathrm{~mm}$ glutathione to the solution led to ph decrease to the values of 1-2 that was accompanied with the appearance of an absorption band at $328 \mathrm{~nm}$ (Figure 5, Curve 3). Subsequent subtraction of Spectrum 2 from Spectrum 3 led to the appearance of an absorption band at 334 $\mathrm{nm}$ (Figure 5, Curve 4) hypothetically generated by GS-NO whose

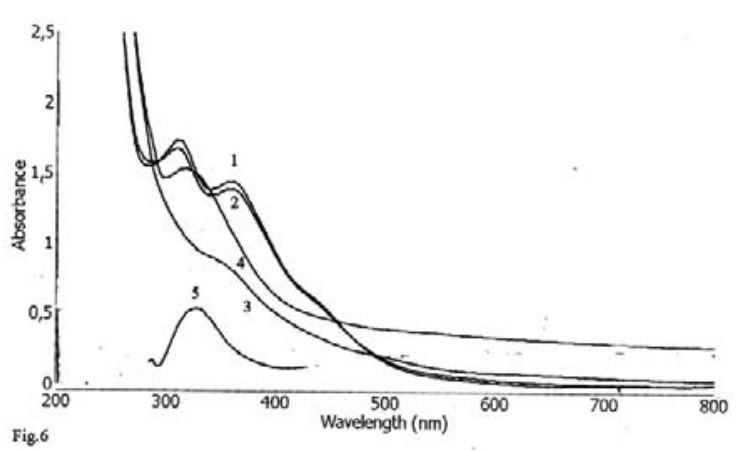

Figure 6: The successive conversion of B-DNIC-GSH into nitrite and GS-NO initiated by treatment of their $0.5 \mathrm{mM}$ solutions with $1.5 \mathrm{mM} \mathrm{PCMB}$ at $\mathrm{pH} 10.0$ and subsequent addition of $6 \mathrm{mM} \mathrm{GSH}(\mathrm{pH} 1-2)$.

Spectrum 1: an original $0.5 \mathrm{mM}$ solution of B-DNIC-GSH (pH 7.3); Spectrum 2: the same after the increase of $\mathrm{pH}$ to 10 ; Spectra 3 and 4: after successive treatment of B-DNIC-GSH with PCMB and GSH (pH 1-2); Spectrum 5: after subtraction of Spectrum 3 from Spectrum 4 suggesting the formation of 0.5mM GS-NO.

concentration was the same as that of original B-DNIC $(0.5 \mathrm{mM})$.

These findings prompt a conclusion that the formation of $0.5 \mathrm{mM}$ GS-NO in the final steps of these experiments was initiated by the release of nitrite anions from decomposing B-DNIC. After acidification of B-DNIC solutions, nitrite anions were converted into nitrous acid able to S-nitrosate glutathione. However, another question arises: was nitrite formation during heating of B-DNIC solutions at neutral $\mathrm{pH}$ be a result of hydrolysis of nitrosonium ions in B-DNIC, or was nitrite formed by a more common route as was proposed in [31]? In the framework of the latter hypothesis, the decomposition of B-DNIC solutions was accompanied by generation of free NO; subsequent oxidation of the latter to $\mathrm{NO}_{2}$ by atmospheric oxygen led to the formation of nitrogen trioxide responsible for S-nitrosation of glutathione. This pathway is highly plausible, especially if we take into consideration the fact that in the aforecited study GS-NO appeared in B-DNIC solutions only after their incubation in the air, but was not formed when the experiments were carried out in a degassed Thunberg apparatus.

The choice of the former mechanism of GS-NO formation relied on the following data. In one of our experiments carried out about 10 years ago [11], we succeeded in demonstrating that incorporation of NO molecules in the form of nitrosyl ligands into DNIC with proteinbound thiol-containing ligands decreased the rate of their interaction with superoxide anions by more than three orders of magnitude in comparison with free NO. It may therefore be conjectured that the rate of oxygen-induced oxidation of NO molecules bound to B-DNIC with the thiol-containing tripeptide glutathione would diminish in a similar way. With allowance for the second- and first-order reactions for $\mathrm{NO}$ and oxygen, respectively, and taking the initial concentrations of $\mathrm{NO}$ and $\mathrm{O}_{2}$ at $80^{\circ} \mathrm{C}$ equal to $0.5 \mathrm{mM}$ and $30 \mu \mathrm{M}$, respectively, and the rate constant equal to $2 \times 10^{6} \mathrm{M}^{-2} \mathrm{~s}^{-1}$, the calculated value of the initial rate of free NO oxidation by atmospheric oxygen would be equal to $120 \mu \mathrm{M} / \mathrm{s}$, while the mean rate between the beginning and termination of this process would not exceed $60 \mu \mathrm{M} / \mathrm{s}$. At this reaction rate, which would diminish progressively with the NO expenditure, the oxidation of $1 \mathrm{mM}$ NO would be complete within $\leq 20$ s. If the rate constant of this reaction decreases by three orders of magnitude, this oxidation 

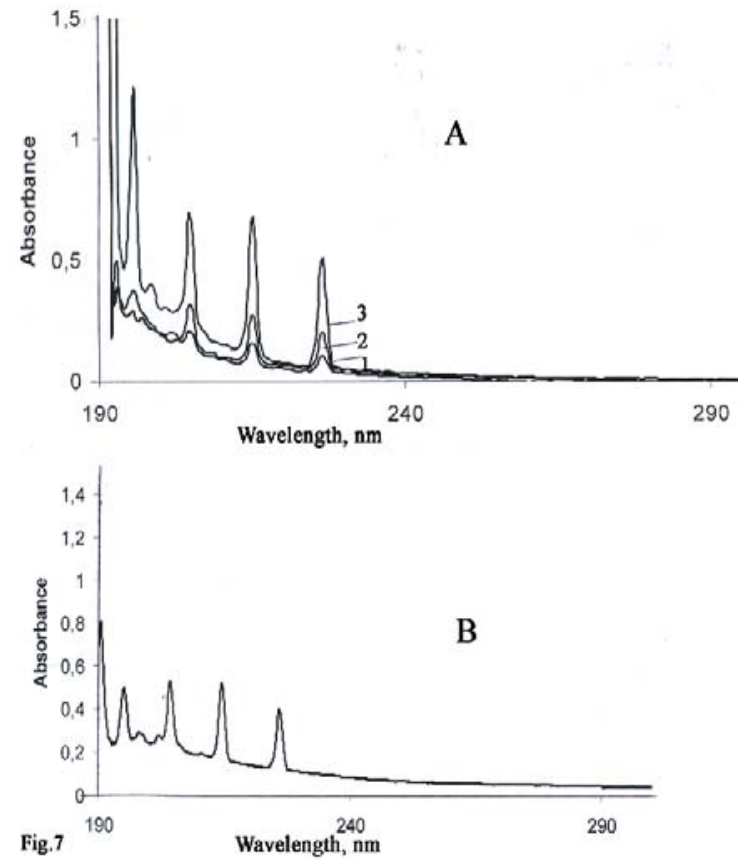

Figure 7: Panel A: The optical absorption spectra of gaseous NO (four narrow equidistant lines $[31,35])$ recorded after decomposition of a $12 \mathrm{mM}$ solution $(17 \mathrm{~mL})$ of B-DNIC-GSH (pH 1.0) induced by heating at $80^{\circ} \mathrm{C}$ for 3,10 or 60 min (Curves $1-3$, respectively). Panel B: The absorption spectrum of a standard specimen of gaseous NO $(430 \mu$ moles in $200 \mathrm{ml}$ of the free volume of the Thunberg apparatus).

rate would exceed $10^{4} \mathrm{~s}(\leq 3 \mathrm{~h})$, which disagrees with our experimental data.

These data provide strong evidence that nitrite formation from decomposing B-DNIC is induced by hydrolysis of nitrosonium ions present in them (Scheme 3). Since in our studies B-DNIC decomposition was notably decelerated in the presence of glutathione added to the complexes at concentrations exceeding those of B-DNIC 3-4-fold, it may be conjectured that this decomposition was initiated by oxidation of thiol groups in B-DNIC by glutathione and their release from the complexes. Indeed, the decomposition of irondinitrosyl fragments in DNIC was accompanied by a release of both NO molecules and nitrosonium ions (Scheme 3). In the absence of thiols, the latter underwent instantaneous hydrolysis to nitrite at neutral $\mathrm{pH}$ (Reaction 2 in Scheme 5):

$$
\mathrm{H}_{2} \mathrm{O}+\mathrm{NO}^{+} \Rightarrow \mathrm{NO}_{2}^{-}+\mathrm{H}^{+}(\text {Reaction } 2)
$$

With a 3-fold increase in the concentration of free GSH in B-DNIC-GSH solutions and the resulting increase in the free GSH:B-DNIC-GSH ratio from 3:1 to 10:1, the rate of decomposition of B-DNIC-GSH upon heating to $80^{\circ} \mathrm{C}$ at neutral $\mathrm{pH}$ decreased dramatically as could be evidenced from the fact that B-DNIC-GSH preserved fully their stability in the solution within at least 1 hour.

\section{Release of nitrite from aqueous solutions of B-DNIC} induced by $\mathrm{p}$-chloromercurybenzoate (PCMB)

The hypothesis on the release of nitrite ions after removal of thiol-containing ligands (glutathione) from B-DNIC is in good accord with the results of my experiments on treatment of B-DNIC with $p$-chloromercurybenzoate (PCMB) (a selective reagent for thiol groups). This compound is endowed with an ability to initiate selective binding of mercury ions to thiol groups resulting in complex decomposition. Considering that PCMB is soluble only in alkaline solutions, in our studies we used $0.5 \mathrm{mM}$ solutions of B-DNIC in $15 \mathrm{mM}$ HEPES prealkalified to $\mathrm{pH} 9-10$, which did not influence the optical characteristics of the complexes (Figure 6, Spectra 1 and 2). Subsequent addition of $1.5 \mathrm{mM}$ PCMB to B-DNIC solutions initiated fast (2-3 min) decomposition of B-DNIC as could be evidenced from the disappearance of their characteristic absorption bands (Figure 6, Spectrum 3). After such treatment, the $\mathrm{pH}$ of B-DNIC solutions decreased to neutral values (7.2-2.4). Further decreases in $\mathrm{pH}$ to acidic values ( $\mathrm{pH} 1-2)$ and addition of glutathione to B-DNIC solutions at concentrations strongly exceeding that of PCMB (6 mM) caused significant changes in the shape of the absorption spectrum of B-DNIC (Figure 6, Spectrum 4).

Subtraction of Spectrum 3 from Spectrum 4 gave an absorption band whose position and shape did not differ from those of GSNO (Figure 6, Spectrum 5); its intensity corresponded to $0.5 \mathrm{mM}$ GS-NO, being equivalent to the concentration of original B-DNIC estimated from the concentration of $\mathrm{Fe}(\mathrm{NO})_{2}$ fragments in these complexes. So, in this case, too, PCMB-induced decomposition of $\mathrm{B}-\mathrm{DNIC}$ was accompanied by a release of nitrosonium ions; further hydrolysis of B-DNIC stimulated the appearance of nitrite anions in B-DNIC solutions at neutral $\mathrm{pH}$. The concentration of nitrite anions was determined from the concentration of GS-NO formed in acidified solutions of B-DNIC as a result of interaction of protonated nitrite with free (non-bound to PCMB) glutathione. As in our previous studies designed to investigate the release of nitrosonium ions from B-DNIC-GSH upon heating of their acidified solutions, the concentration of nitrosonium ions released from B-DNIC in the presence of $\mathrm{PCMB}$ was equivalent to the concentration of $50 \%$ of nitrosyl ligands present in B-DNIC suggesting that in this series of our experiments the rest $50 \%$ of the ligands were released from B-DNIC in the form of neutral NO molecules.

\section{Release of NO from acidified solutions of B-DNIC with glutathione after long-term heating to $80^{\circ} \mathrm{C}$}

As above, 15-min heating of acidified solutions of B-DNIC with glutathione $(9 \mathrm{mM})$ to $80^{\circ} \mathrm{C}$ resulted in the appearance in test solutions of GS-NO at a concentration equivalent to the concentration of the soluble complexes (Figure 3, Panel D). We hypothesized that under these conditions $50 \%$ of the nitrosyl ligands present in B-DNIC left the complexes in the form of nitrosonium ions, while the rest $50 \%$ were released in the form of neutral (gaseous) molecules of NO. This hypothesis was confirmed by experiments on heating of $12 \mathrm{mM}$ solution of B-DNIC with glutathione $(17 \mathrm{ml})(\mathrm{pH} 1-2)\left(80^{\circ} \mathrm{C}, 60 \mathrm{~min}\right)$ in a degassed Thunberg apparatus. The concentration of gaseous NO was measured spectrophotometrically from the intensity of the 4-component absorption spectrum in the range between 220 and 190 $\mathrm{nm}[43,46]$ (Figure 7 ) using a cylinder-shaped quartz cuvette soldered up to the Thunberg apparatus (Figure 1B).

The measurements of NO in the gaseous phase were performed 3,10 and $60 \mathrm{~min}$ after the onset of heating of test solutions (Figure 7, Panel A, Curves 1-3, respectively). After 1h, the concentration of $\mathrm{NO}$ in the gaseous phase reached $410 \mu$ moles, which corresponded to the conversion of all nitrosyl ligands in B-DNIC into NO as could be evidenced from a comparison of the absorption spectra of $\mathrm{NO}$ 


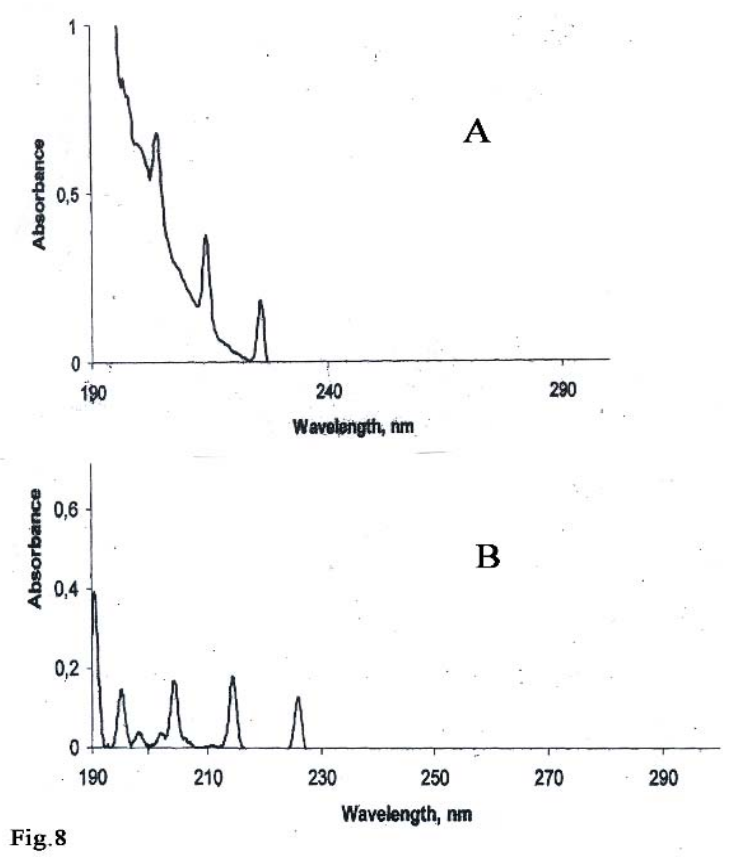

Figure 8: Panel A: The optical absorption spectra of gaseous NO (four narrow equidistant lines $[31,35]$ ) obtained during decomposition of a $7 \mathrm{mM}$ solution $(16 \mathrm{~mL})$ of B-DNIC-GSH induced by treatment of test solutions with $15 \mathrm{mM}$ $p C M B$. The broad structureless absorption spectrum is due to the presence in the gaseous phase of an ( $\mathrm{NO}_{2}$ ) [31] admixture formed upon decomposition of nitrous acid. Panel B: The absorption spectrum of a standard specimen of gaseous NO $(220 \mu$ moles in $200 \mathrm{ml}$ of the free volume of the Thunberg apparatus).

presented in Panel A, Curve 3 to that of the standard specimen of gaseous NO (Figure 7, Panel B). After 15-20 min, i.e., by the time when $50 \%$ of the nitrosyl ligands were hypothetically converted into GS-NO, the gaseous phase contained $\sim 200 \mu$ moles NO, reaching the maximum level within the next 35-40 min (data not shown).

These experiments clearly demonstrated that during the first 15-20 min of heating the formation of GS-NO, which contained $50 \%$ (200 $\mu$ moles) of nitrosyl ligands, was indeed accompanied by decomposition of B-DNIC (according to Scheme 3) after which the rest $50 \%$ of nitrosyl ligands within the composition of B-DNIC were released into the gaseous phase in the form of neutral molecules of NO, evidently, due to decomposition of GS-NO formed in the process. Quite probably, under these conditions iron or copper ions present in GS-NO preparations as admixtures played the role of catalysts in the reduction of GS-NO NO${ }^{+}$to $\mathrm{NO}[48,49]$ (Reaction 3) resulting in GS-NO decomposition:

$$
\text { GS }^{-} \mathrm{NO}^{+} \Leftarrow \Rightarrow \mathrm{GS}^{*}+\mathrm{NO}
$$

(Reaction 3)

This reaction was accompanied by conversion of the thiol component of S-nitrosothiol into the thyil (GS*) radical; binding of the latter to GS or another thyil radical resulted gave reduced (or non-reduced) disulfide, respectively.

This finding is in complete agreement with our previous data [43] suggesting that decomposition of acidified solutions of $0.3 \mathrm{mM}$ B-DNIC-GSH is concomitant with a release of all nitrosyl ligands present in original B-DNIC in the form of neutral molecules of
NO.

\section{Release of NO in aqueous solutions of B-DNIC with glutathione induced by $\mathrm{PCMB}$}

As stated earlier (Figure 6), PCMB-induced decomposition of B-DNIC was accompanied by a hypothetical release of both nitrite and gaseous NO. Our experiments designed to examine this hypothesis established that PCMB-induced decomposition of B-DNIC is indeed concomitant with the appearance of significant amounts of $\mathrm{NO}$ in the gaseous phase. A solution of $p \mathrm{CMB}$ ( $\mathrm{pH}$ 10.0) was loaded into the upper chamber of a degassed Thunberg apparatus and mixed in vacuo with $16 \mathrm{ml}$ of a $7 \mathrm{mM}$ solution of B-DNIC-GSH loaded into the lower chamber of the apparatus to a final concentration of PCMB $15 \mathrm{mM}$. Violent bubbling of NO released from B-DNIC was observed immediately after mixing of the reaction components concomitantly with acidification of test solutions. The concentration of NO in the gaseous phase was determined after termination of bubbling, viz., $\sim 10$ min after the onset of mixing (Figure 8, Panel A).

At this stage, the gaseous phase contained up to 180-190 $\mu$ moles of NO, which corresponded to the release of $\sim 75-80 \%$ of nitrosyl ligands present in B-DNIC-GSH in the form of neutral NO molecules. According to Scheme 3,110 $\mu$ moles of NO were released from B-DNIC in the form of NO molecules, whereas the appearance of other NO molecules in the gaseous phase must be initiated by the interaction of nitrosonium ions released from B-DNIC in the amount of $110 \mu$ moles with an acid medium where these ions were converted into nitrous acid (110 $\mu$ moles) as a result of hydrolysis. Subsequent disproportionation of two molecules of nitrous acid must be accompanied by a release of $55 \mu$ moles of $\mathrm{NO}$ and $55 \mu$ moles of $\mathrm{NO}_{2}$ (Reaction 4):

$$
2 \mathrm{HNO}_{2} \Leftarrow \Rightarrow \mathrm{NO}+\mathrm{NO}_{2}+\mathrm{H}_{2} \mathrm{O}
$$

(Reaction 4)

The greater part of NO, which is poorly soluble in water, passed into the gaseous phase, while $\mathrm{NO}_{2}$ molecules might undergo disproportionation in water to generate equal amounts of nitronium cations $\left(\mathrm{NO}_{2}^{+}\right)$and nitrite anions $\left(\mathrm{NO}_{2}\right)$; their hydrolysis gave equal (27.5 $\mu$ moles) amounts of nitric and nitrous acid, respectively. Subsequent disproportionation of two molecules of nitrous acid caused a further release of $13.7 \mu$ moles of $\mathrm{NO}$ and $\mathrm{NO}_{2}$ into the gaseous phase and water, respectively, and so forth. In this continuous round of events, up to 70-75 $\mu$ moles of $\mathrm{NO}$ and $~ 35-40 \mu$ moles of nitric acid were accumulated in the gaseous and aqueous phases, respectively. In total, out of $220 \mu$ moles of nitrosyl ligands $\sim 180 \mu$ moles passed into the gaseous phase in the form of neutral molecules of NO, and the rest $\sim 40 \mu$ moles of nitric acid was accumulated in water.

\section{Discussion}

The totality of experimental data give me good reason to assert that nitrosonium ions as well as $\mathrm{NO}$ molecules can be regarded as indispensable components of B-DNIC-GSH. Being released from the complexes, $\mathrm{NO}^{+}$ions exert S-nitrosation of thiols by initiating the synthesis of GS-NO as was the case in our studies. Because of this, B-DNIC-GSH and, probably, other B- and M- DNIC with thiolcontaining ligands can be assigned to the class of $\mathrm{NO}^{+}$-containing compounds, which also include nitrogen trioxide, RS-NO and nitrous acid the nitrosonium ion in which is responsible for their S-nitrosating activity. 
It would be reasonable to assume that fast (within $\leq 1 \mathrm{~min}$ ) appearance of GS-NO in acidified $0.5 \mathrm{mM}$ solutions of B-DNIC after heating to $80^{\circ} \mathrm{C}$ both in the presence and in the absence of oxygen is very similar to the phenomenon described by Hogg et al. [31], viz., gradual (24h) accumulation of GS-NO in acidified solutions of B-DNIC-GSH. Their concentration was equimolar to the concentration of $50 \%$ of the nitrosyl ligands present in decomposing B-DNIC after incubation of the latter at ambient temperature. The same is true of the differences between the rates of GS-NO formation in the aforecited and our study, viz., 24h in [31] and 30s in this study.

Two factors can be responsible for this discrepancy, and the first of them is temperature difference as a factor accelerating chemical processes. In our study, the rate of GS-NO formation decreased significantly (as can be judged from the increase of the time of formation of DNIC from 30s to 15-20 min, respectively) with a drop in temperature from $80^{\circ} \mathrm{C}$ to $40^{\circ} \mathrm{C}$. The second factor is the difference between the concentration ratios of free (non-incorporated into B-DNIC-GSH) GSH and B-DNIC. In the study by Hogg et al., this ratio was 20:1, that in our study was 3:1. Noteworthy, in our study the decomposition of B-DNIC-GSH was sharply decelerated after the increase of the aforesaid ratio to $10: 1$, and ceased completely during at least $1 \mathrm{~h}$.

The unexpectedly high resistance of B-DNIC to acidification at ambient temperature first established in our previous study [42] seems amazing at first sight, since it was anticipated that acidification would inevitably initiate the protonation of thiol groups of glutathione, which play the role of bridges linking together the $\mathrm{Fe}(\mathrm{NO})_{2}$ fragments in B-DNIC, eventually resulting in decomposition of B-DNIC.

A natural question arises: what is the factor responsible for the lack of protonation of sulfur atoms and, as a consequence, for B-DNIC-GSH preservation in strongly acidic solutions? Earlier we conjectured [41,42] that high stability of B-DNIC in acidified solutions is a result of decreasing electron density on thiol sulfur atoms, which leads to "denudation" of their electronic shells. This phenomenon can be attributed to extremely high $\pi$-donor activity of thiol sulfur atoms, on the one hand, and to high $\pi$-acceptor activity of iron-dinitrosyl fragments in B-DNIC, on the other hand. Since thiol sulfur atoms in B-DNIC play the role of bridges linking together two iron-dinitrosyl fragments, the latter can take up a considerable amount of electron density from sulfur atoms, which ultimately inhibits their protonation.

Besides, the transfer of electron density from sulfur atoms to iron-dinitrosyl fragments in B-DNIC ensures neutralization of the positive charge on $\mathrm{NO}^{+}$ions which, in its turn, protects the latter from hydrolysis initiated by their interaction with hydroxyl ions. In $\mathrm{M}-\mathrm{DNIC}$, the hydrolysis of $\mathrm{NO}^{+}$ions induced by the same factor is inhibited by a similar mechanism, which testifies to stabilization of both complexes (M- and B-DNIC) at neutral pH [41].

It is apparent that gradual time-dependent protonation of thiol groups in B-DNIC with glutathione makes the basis of irreversible decomposition of B-DNIC in acidified solutions. This process is relatively slow at ambient temperature, e.g., in aqueous solutions ( $\mathrm{pH}$ 1.0 ) the decomposition of $0.1 \mathrm{mM}$ B-DNIC lasts $24 \mathrm{~h}$, as was probably the case in the study by Hogg et al. [31].
A similar situation was observed in our study where fast (30 sec) decomposition of B-DNIC and conversion of $50 \%$ of nitrosyl ligands in GS-NO might be induced by heating to $80^{\circ} \mathrm{C}$. According to Scheme 3 illustrating the release of equivalent amounts of $\mathrm{NO}$ molecules and nitrosonium ions from $\mathrm{M}-\mathrm{DNIC}$, a similar process might take place in the case of B-DNIC (Scheme 6):

In contrast to the equilibrium process depicted in Scheme 3 for M-DNIC, the decomposition of B-DNIC at $\mathrm{pH} 1.0$ is irreversible, which is the reason for GS-NO accumulation in the solution. The irreversibility of this decomposition, i.e., the unfeasibility of regeneration of B-DNIC in acidified solutions, is determined by protonation of virtually all thiol molecules as a result of which these ligands lose their ability to bind to $\mathrm{Fe}^{2+}$ cations.

It is important to note that both in this study and in the study by Hogg et al. [31] the decomposition products of B-DNIC-GSH at neutral $\mathrm{pH}$ included only nitrite ions, but no GS-NO; their concentration correlated with the concentration of $50 \%$ of nitrosyl ligands present in B-DNIC. The results of my study suggest that such decomposition does take place during incubation of B-DNIC-GSH solutions in the air, which can lead to gradual oxidation of GSH and, finally, decomposition of B-DNIC, since the presence in GSH solutions of excessive amounts of B-DNIC notably decelerates the rate of their decomposition. These results suggest the following mechanism of B-DNIC-GSH decomposition as a representative of DNIC with thiolcontaining ligands subject to long-term incubation of the complexes at neutral (physiological) $\mathrm{pH}$, at ambient temperature and upon heating to $80^{\circ} \mathrm{C}$ (Scheme 7):

In the framework of this mechanism, the decrease in the concentration of thiols (GSH) in solutions of B-DNIC with thiolcontaining ligands increases the concentration of nitrosonium ions undergoing irreversible conversion during hydrolysis of nitrite anions and thus initiates the decomposition of B-DNIC. The stability of the latter is provided by RS-NO (GS-NO), which, together with $\mathrm{Fe}^{2+}$ ions and $\mathrm{NO}$, are responsible for regeneration of B-DNIC (Schemes 4 and 7).

The hypothetical mechanism of B-DNIC-GSH decomposition at neutral ("physiological") $\mathrm{pH}$ is fully consistent with the results of our experiments, according to which this process is initiated by PCMB or, more exactly, by their constituent components, viz., mercury ions. As it is known, interactions of these ions with RS-NO lead to their decomposition concomitantly with the appearance in test solutions of nitrite anions as a result of hydrolysis of nitrosonium ions released from RS-NO after binding of mercury ions to their thiol groups. A similar mechanism can underlie the formation of nitrite anions (as was the case in this study) by treatment of $0.5 \mathrm{mM}$ solutions of B-DNIC-GSH with PCMB at neutral $\mathrm{pH}$.

Treatment of concentrated $(5 \mathrm{mM})$ solutions of B-DNICGSH with PCMB resulted in the conversion of the greater part of nitrosyl ligands (80-85\%) into neutral (gaseous) NO molecules (Figure 8). Their appearance can be attributed to acidification of B-DNIC solution in the course of their hydrolysis by excess $(5 \mathrm{mM})$ concentrations of nitrosonium ions, which seems to be the main reason for enhanced accumulation of protons in test solutions and, finally, their acidification. 


\section{Conclusion}

It must be said in conclusion that the presence in DNIC with glutathione and, probably, with other thiol-containing ligands of $\mathrm{S}$-nitrosating activity is determined by the $\mathrm{d}^{7}$ electronic configuration of their iron atom in the dinitrosyl-iron- $\mathrm{Fe}^{+}\left(\mathrm{NO}^{+}\right)_{2}$ fragment of DNIC, which is responsible for the ability of these complexes to release equal amounts of neutral NO molecules and nitrosonium ions by Scheme 3. It is precisely this ability that determines the biological avtivity of DNIC with thiol-containing ligands mimicking various biological effects of endogenous $\mathrm{NO}$ as a universal regulator of miscellaneous metabolic processes. These findings testify to the high clinical perspectiveness of these DNIC as a base in the design of medicinal drugs possessing a broad range of therapeutic activities.

As regards the alternative $\left(\mathrm{d}^{9}\right)$ electronic configuration of the iron atom in DNIC with thiol-containing ligands suggested by some authors [50-53], it does not provide an explicit explanation for the presence in these complexes of nitrosonium ions as their constituent components. In this context, the chemical equilibrium between the thiol-Fe-dinitrosyl fragment of M-DNIC described by the formula (RS) $)_{2} \mathrm{Fe}^{-1}\left(\mathrm{NO}^{+}\right)_{2}$ and characteristic of the $\mathrm{d}^{9}$ configuration and their constituent components would more adequately be described by Scheme 8:

From Scheme 8 it follows that the appearance of $\mathrm{NO}^{+}$among other components of the chemical equilibrium for DNIC with thiolcontaining ligands having the $\mathrm{d}^{9}$ electronic configuration of the iron atom can hardly be expected. As regards neutral molecules of NO and negatively charged nitroxyl ions (NO), they are devoid of the ability to interact with thiols with the formation of RS-NO. The latter can take place only after oxidation of $\mathrm{NO}$ and $\mathrm{NO}^{-}$released from decomposing DNIC to $\mathrm{NO}_{2}$.

\section{Acknowledgements}

This work has been carried out in the framework of the State Programs of the Russian Federal Agency for Scientific Organizations (0082-2014-0001, No. AAAA-A17-117040610310-6 0082-2014-0008 and No. AAAA-A17-117040310008-5). The study was sponsored by the Russian Academic Excellence Project "5-100" and supported by the Russian Foundation for Fundamental Research (Grant No. 1804-00059a) and the Russian Scientific Foundation (Grant No. 1613-10295). The author thanks Dr. Rostislav Borodulin, Dr. Nikolay Tkachev, and Dr. Vasak Mikoyan for technical assistance.

\section{References}

1. AL Kleschyov, PI Mordvintcev, AF Vanin. Iron and nitric oxide role in hypotensive activity of dinitrosyl iron complexes with various anionic ligands. Studia Biofizika. 1985; 105: 93-102.

2. YuP Vedernikov, PI Mordvintcev, IV Malenkova, AF Vanin. Similariry between the vasorelaxing activity of dinitrosyl iron complexes and endothelium-derived relaxing factor. Eur J Pharmacology. 1992; 211: 313-317.

3. AF Vanin, VP Mokh, VA Serezhenkov, El Chazov. Vasorelaxing activity of stable powder preparations of dintrosyl iron complexes with cysteine or glutathione. Nitric Oxide Biol Chem. 2007; 16: 322-330.

4. VL Lakomkin, AF Vanin, AA Timoshin, VI Kapel’ko, EI Chazov. Long-lasting hypotensive action of stable preparations of dinitrosyl-iron complexes with thiol-containing ligands in conscious normotensivee and hypertensive rats. Nitric Oxide Biol Chem. 2007; 16: 413-418.

5. PI Mordvintcev, VG Rudneva, AF Vanin, LL Shimkevich, BI Khodorov.
The inhibitory effect of low-molecular dinitrosyl iron complexes on platelet aggregation. Biokhimiya (Rus). 1986: 51: 1851-1857.

6. VA Kuznetsov, PI Mordvintcev, EK Dank, VA Yurkiv, AF Vanin. Lowmolecular and protein-bound dinitrosyl iron complexes as inhibitors of platelet aggregation. Voprosy Med Khimii (Rus). 1988; 5: 43-46.

7. AB Shekhter, TG Rudenko, VA Serezhenkov, AF Vanin. Dinitrosyl-iron complexes with cysteine or glutathione accelerate skin wound healing. Biofizika (Rus). 2007; 52: 539-547.

8. AB Shekhter, TG Rudenko, LP Istranov, AE Guller, RR Borodulin, AF Vanin. Dinitrosyl iron complexes with glutathione incorporated into a collagen matrix as a base for the design of drugs accelerating skin wound healing. Eur $\mathrm{J}$ Pharm Sci. 2015; 78: 8-18.

9. AA Andreev-Andriyevsky, VD Mikoyan, VA Serezhenkov, AF Vanin. Penile erectile activity of dinitrosyl iron complexes with thiol-contasining ligands Nitric Oxide. Biol Chem. 2011; 24: 217-223.

10. FAC Wiegant, IY Malyshev, AL Kleschyov, E van Faassen, AF Vanin. Dinitrosyl iron complexes with thiol-containing ligands and S-nitroso-D,Lpenicillamine as inductors of heat shock protein synthesis in $\mathrm{H} 35$ hepatoma cells. FEBS Lett. 1999; 435: 179-182.

11. KB Shumaev, AA Gubkin, VA Serezhenkov, II Lobysheva, OV Kosmachevskaya, EK Ruuge, et al. Interaction of reactive oxygen and nitrogen species with albumin and methemoglobin-bound dinitrosyl iron complexes. Nitric Oxide Biol Chem. 208; 18: 37-46.

12. VI Kapel'ko, VL Lakomkin, AA Abramov, EV Lukoshenkova, NA Undroninas, AY Kapchaev, et al. Protective effects of dinitrosyl iron complexes under oxidative stress in the heart. Oxidat Med Cell Longevity. 2017; 2017 ID 9456163.

13. KLepka, K Volbracht, E Bill, R Scgneider, N Rios, T Hildebrandt, et al. Ironsulfur glutaredoxin 2 protects oligodendrocytes against damage induced by nitric oxide from activated microglia. Glia. 2017; 65: 1521-1534.

14. H Ding, B Demple. Direct nitric oxide transduction via nitrosylation of ironsulfur centers in the SoxR transcription activation. Proc Natl Acad Sci USA. 2000; 97: 5146-5150.

15. SV Vasilieva, EYu Moshkovskaya, NA Sanina, SM Aldoshuin, AF Vanin. Genetic signal transduction by nitrosyl-iron complexes in Escherichia coli. Biokhimiya (Rus). 2004; 69: 883-889.

16. AA Boldyrev, ER Bulygina, GG Kramarenko, AF Vanin. Effect of nitroso compounds on Na/K-ATPase. Biochim Biophys Acta Bioenerg. 1997; 1321: 243-251.

17. M Boese, MA Keese, K Becker, R Busse, A Mülsh. Inhibition of glutathione reductase by dinitrosyl-iron-dithiolate complex. J Biol Chem. 1997; 272: 21767-21773.

18. MA Keese, M Boese, A Mülsch, RH Schrimer, K Becker. Dinitrosyl-dithiol-iron complexes, nitric oxide (NO) carriers in vivo as a potent inhibitors of human glutathione reductase and glutathione-S-transferase. Biochim Pharmacol. 1997; 54: 1307-1313.

19. NV Voevodskaya, VA Serezhenkov, CE Cooper, L/N Kubrina, AF Vanin. Exogenous iron is required for the nitric oxide-catalyzed destruction of the iron-sulfur center in adrenodoxin. Biochem J. 2002; 368: 633-639.

20. AF Vanin, IV Malenkova, PI Mordvintcev, A Mülsch. Dinitrosyl iron complexes with thiol-containing ligands and their reversible conversion into nitrosothiols. Biokhimiya (Rus). 1993; 58: 1094-1103.

21. M Boese, PI Mordvintcev, AF Vanin, R Busse, A Mülsch. S-nitrosation of serum albumin by dinitrosyl-iron complex. J Biol Chem. 1995; 270: $29244-$ 29249.

22. CA Bosworth, JC Toledo, JW Zmiewski, JR Lancaster. Dinitrosyliron complex and the mechanism(s) of cellular protein nitrosothiol formation. Proc Natl Acad Sci USA. 2009; 106: 4671-4676.

23. MV Foster, L Liu, M Zeng, DT Hess, JS Stamler. A genetic analysis of nitrosative stress. Biochemistry. 2009; 48: 792-799.

24. C Badorff, B Fichtscherer, A Muelsch, AM Zeiher, S Dimmeler. Selective 
delivery of nitric oxide to a cellular target: a pseudosubstrate-coupled dinitrosyl-iron complex inhibits the enteroviral protese 2A. Nitric Oxide Biol Chem. 2002; 6: 305-312.

25. AF Vanin, EN Burgova, LV Adamyan. Dinitrosyl iron complexes with glutathione suppress surgically induced experimental endometriosis in rats. Austin J Reproductive Medicine \& Infertility. 2015; 2: 1-7.

26. AL Kleschyov, S Stand, S Schmitt, D Gottfried, M Skatchkov, N Sjakste, et al. Dinitrosyl-iron triggers apoptosis in Jurkat cells despite overexpression of $\mathrm{Bcl}^{-2}$. Free Rad Biol Med. 2006; 40: 1340-1348.

27. S-C Wu, C-Y Lu, U-L Chen, F-C Lo, T-Y Wang, Y-J Chen, et al. Water-soluble dinitrosyl iron complex (DNIC): a nitric oxide vechicle triggering cancer cell death via apoptosis. Inorg Chem. 2016; 55: 9383-9392.

28. AF Vanin, LA Ostrovskaya, DB Korman. Antitumour activity of dinitrosyl iron complexes with thiol-containing ligands in animals: an overview. Austin J Analyt Pharmac Chem. 2018; 5: 1104-1116.

29. El Chazov, OV Rodnenkov, AV Zorin, VL Lakomkin, VV Gramovich, OV Vyborov, et al. Hypotensive effect of "Oxacom" containing a dinitrosyl iron complex with glutathione: animal studies and clinical trials on healthy volunteers. Nitric Oxide Biol Chem. 2012; 26: 148-157.

30. A Mülsch, PI Mordvintcev, AF Vanin, R Busse. The potent vasodilating and guanylyl cyclase activating dinitrosyl-iron(II) complex is stored in a proteinbound form in vascular tissue and is released by thiols. FEBS Lett. 1991; 294: 252-256.

31. Keszler A, Diers AR, Ding Z, Hogg N. Thiolate-based dinitrosyl iron complexes: decomposition, detection and differentiation from S-nitrosothiols. Nitric Oxide Biol Chem. 2017; 65: 1-9.

32. JH Enemark, RD Feltham. Prinnciples of structure, bonding, and reactivity for metal nitrosyl. Coord Chem Rev. 1974; 13: 339-406.

33. AF Vanin, IV Malenkova, VA Serezhenkov. Iron catalyzes both decomposition and synthesis of S-nitrosothiols: optical and EPR studies. Nitric Oxide Biol Chem. 1997; 1: 191-203.

34. AF Vanin. Dinitrosyl iron complexes with thiolate ligands: physico-chemistry biology, and physiology. Nitric Oxide Biol Chem. 2009; 21: 1-13.

35. AF Vanin. EPR characterization of dinitrosyl iron complexes with thiolcontaining ligands as an approach to their identification in biological objects: An overview. Cell Biochem Biophys. 2018; 76: 3-17.

36. B D`Autreaux, O Horner, JL Oddou, C Jeandey, S Gambarelli, C Berthomieu, et al. Spectroscopic description of the two nitrosyl-iron complexes responsible for Fur inhibition by nitric oxide. J Am Chem Soc. 2004; 126: 6005-6016.

37. S Stojanovic, D Stanic, M Nicolic, M Spasic, V Niketic. Iron catalyzed conversion of $\mathrm{NO}$ into nitrosonoum $\left(\mathrm{NO}^{+}\right)$and nitroxyl (NO-) species. Nitric Oxide Biol Chem. 2004; 11: 256-262.

38. AF Vanin, RM Nalbandyan. Free radicals of a new type in yeast cells. Biofizika (Rus). 1965; 10: 167-168.

39. AJ Vithaythil, B Ternberg, B Commoner. Electron spin resonance signals of rat liver during chemical carcinogenesis. Nature. 1965; 207: 1246-1249.
40. AF Vanin, LA Blumenfeld, AG Chetverikov. Investigation of non-heme iron complexes in cells and tissues by the EPR method. Biofizika (Rus). 1967; 12: 829-841.

41. AF Vanin, DSh Burbaev. Electronic and spatial structures of water-soluble dinitrosyl iron complexes with thiol-containing ligands underlying their activity as nitric oxide and nitrosonium ion donors. Biophys J. 2011; 14

42. AF Vanin, AP Poltorakov, VD Mikoyan, LN Kubrina, DSh Burbaev. Polynuclear water-soluble dinitrosyl Iron complexes with cysteine or glutathione ligands: electron paramagnetic resonance and optical studies. Nitric Oxide Biol Chem. 2010; 23: 1236-1249.

43. RR Borodulin, LN Kubrina, VD Mikoyan, AP Poltorakov, VO Shvydkiy, DSh Burbaev, et al. Dinitrosyl iron complexes with glutathione as NO and NO donors. Nitric Oxide Biol Chem. 2013; 29: 4-16.

44. AF Vanin, AA Papina, VA Serezhenkov, WH Koppenol. The mechanism of S-nitrosothiol decomposition catalyzed by iron. Nitric Oxide Biol Chem. 2004; 10: $60-73$.

45. RR Borodulin, LN Kubrina, VO Shvydkiy, VL Lakomkin, AF Vanin. A simple protocol for the synthesis of dinitrosyl iron complexes with glutathione: EPR, optical, chromatographic and biological haracterization of reaction products". Nitric Oxide Biol Chem. 2013; 35: 110-115.

46. J Lique, DR Crosley. Transition probabilities and electron transition moments of the A2+-X2II and D2+-X2II system of nitric oxide. J Chem Phys. 1999; 111: $7405-7411$

47. DSh Burbaev, AF Vanin, LA Blumenfeld. Electronic and spatial structures of paramagnetic dinitrosyl ferrous complexes. Zhurnal Strukt Khimii (Rus). 1971; 2: 252-256

48. J McAninly, DLH Williams, SC Ascew, AR Butler, C Russel. Metal ions catalysis of nitrosothiols (RS-NO) decomposition. J Chem Soc Chem Comm. 1993; 93: 1758-1759.

49. JS Stamler, EJ Toone. The decomposition of trinitrites. Current Opinion in Chemical Biology. 2002; 6: 779-785.

50. CC Tsou, TT Lu, WF Liaw. EPR, UV-vis and X-ray demonstration for the anionic dimeric dinitrosyl iron complexes $\left[(\mathrm{NO})_{z} \mathrm{Fe}_{2}(\mathrm{SBut})_{2}(\mathrm{NO})_{2}\right]$ : relevance to the product of nitrosylation of cytosolic and tochondrial aconitases, and high-potential iron proteins. J Am Chem Soc. 2007; 129: 12626-12627.

51. TT Lu, CC Tsou, HW Huang, IJ Hsu, JM Chen, TS Kuo, et al. Anionic Rossin`s Red Ethers (RREs)syn-lanti-[Fe-SE'(NO) $]_{2}$ : the critical role of thiolate ligands in regulating the transformation of RREs. Inorganic Chem. 2008; 47: 60406050.

52. CC Tinberg, ZJ Tonzetic, H Wang, LH Do, Y Yoda, SP Cramer, et al. J Am Chem Soc. 2010; 132: 18168-18176.

53. AF Shestakov, YuM Shul'ga, NS Emel yanova, NA Sanina, SM Aldoshin. Molecular and electronic structures and IR spectra of mononuclear dinitrosyl iron complex $\left[\mathrm{Fe}\left(\mathrm{SC}_{2} \mathrm{H}_{3} \mathrm{~N}_{3}\right)_{2}(\mathrm{NO})_{2}\right]$ : a theoretical study. Russian Chemical Bulleten. 2007; 56: 1289-1297.
Austin J Anal Pharm Chem - Volume 5 Issue 3 - 2018 ISSN : 2381-8913 | www.austinpublishing roup.com Vanin. (C) All rights are reserved
Citation: Vanin AF. Nitrosonium lons as Constituents of Dinitrosyl Iron Complexes with Glutathione Responsible for their S-Nitrosating Activity. Austin J Anal Pharm Chem. 2018; 5(3): 1109 